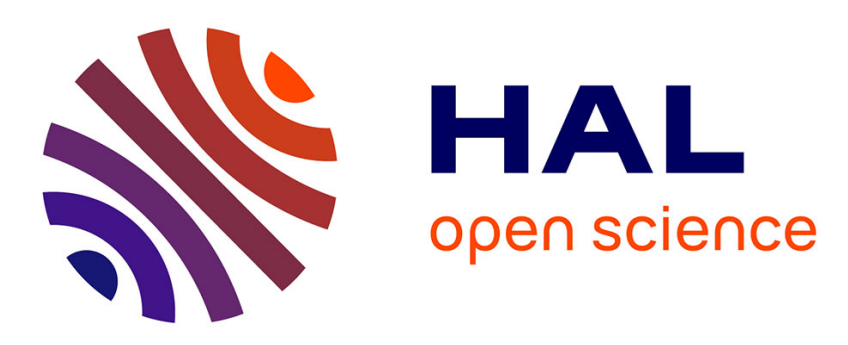

\title{
Influence of bottom roughness and ambient pressure conditions on the emplacement of experimental dam-break granular flows
}

Santiago Montserrat, Lady Ordoñez, Aldo Tamburrino, Olivier Roche

\section{To cite this version:}

Santiago Montserrat, Lady Ordoñez, Aldo Tamburrino, Olivier Roche. Influence of bottom roughness and ambient pressure conditions on the emplacement of experimental dam-break granular flows. Granular Matter, 2021, 23 (3), 10.1007/s10035-021-01125-2 . hal-03254037

\author{
HAL Id: hal-03254037 \\ https://hal.uca.fr/hal-03254037
}

Submitted on 16 Jun 2021

HAL is a multi-disciplinary open access archive for the deposit and dissemination of scientific research documents, whether they are published or not. The documents may come from teaching and research institutions in France or abroad, or from public or private research centers.
L'archive ouverte pluridisciplinaire $\mathbf{H A L}$, est destinée au dépôt et à la diffusion de documents scientifiques de niveau recherche, publiés ou non, émanant des établissements d'enseignement et de recherche français ou étrangers, des laboratoires publics ou privés.

\section{(ㄷ)(1)}

Distributed under a Creative Commons Attribution| 4.0 International License 
Noname manuscript No.

(will be inserted by the editor)

\title{
Influence of bottom roughness and ambient pressure conditions on the emplacement of experimental dam-break granular flows
}

\author{
Santiago Montserrat • Lady Ordoñez • \\ Aldo Tamburrino • Olivier Roche. \\ 7 Received: DD Month YEAR / Accepted: DD Month YEAR
}

Abstract Geophysical granular flows occur at the surface of the Earth and other planets with reduced atmospheric pressure. In this paper, we investigate the run-out of dam-break flows of particle-air mixtures with fine $(d=75 \mu \mathrm{m})$ 1 or coarse $(d=150 \mu \mathrm{m})$ grains in a flume with different bottom roughness $(\delta)$ 12 and vacuum degrees $\left(P^{*}\right)$. Our results reveal an increase of the flow run-out 13 as $d / \delta$ decreases for fine $d=75 \mu \mathrm{m}$-particles, and run-out decreases with the 14 dimensionless ambient pressure $\left(P^{*}\right)$ for a given $d / \delta$. In contrast, the run-out

S. Montserrat

Advanced Mining Technology Center-AMTC, Universidad de Chile, Av. Tupper 2007, 8370451, Santiago, Chile

Tel.: +56-2-29771010

E-mail: santiago.montserrat@amtc.cl

L. Ordoñez

Advanced Mining Technology Center-AMTC, Universidad de Chile, Av. Tupper 2007, 8370451, Santiago, Chile

Departamento de Ingeniería Civil, Universidad de Chile, Av. Blanco Encalada 2002, 8370449, Santiago, Chile

Tel.: +56-2-29784400

E-mail: lady_ordonez@hotmail.es

A. Tamburrino

Departamento de Ingeniería Civil, Universidad de Chile, Av. Blanco Encalada 2002, 8370449, Santiago, Chile

Advanced Mining Technology Center-AMTC, Universidad de Chile, Av. Tupper 2007, 8370451, Santiago, Chile

Tel.: +56-2-29784400

E-mail: atamburr@ing.uchile@cl

O. Roche

Laboratoire Magmas et Volcans, Université Blaise Pascal-CNRS-IRD, OPGC Campus Universitaire des Cézeaux, 6 Avenue Blaise Pascal, TSA 60026 - CS 60026, 63178 AUBIERE,Cedex, France

Tel.: +33-4-73346768

E-mail: olivier.roche@uca.fr 
for coarser $d=150 \mu m$-particles, is almost invariant respect to $P^{*}$ and $d / \delta$. These results show that autofluidization of fine-grained flows demonstrated by earlier works at ambient pressure also occurs at reduced pressure though being less efficient. Hence, autofluidization is a mechanism, among others, to explain long run-out of geophysical flows in different environments.

Keywords Dam-break · Granular flows · Pore pressure · Ambient pressure • Fluidization · Substrate roughness

\section{Introduction}

The run-out distance of dense geophysical granular flows is commonly larger than expected because the apparent friction angle is significantly reduced with respect to the repose angle of same geological materials Legros (2002); Iverson (1997); Delannay et al. (2017). Friction reduction mechanisms have been attributed for instance to the formation of a low density bottom layer, caused by grains interacting with the bottom Cleary and Campbell (1993); Bartelt et al. (2006); Brodu et al. (2015), and/or to particle-fluid interactions causing fluidization Iverson (1997); Roche et al. (2008). However, long run-outs have been observed for flows at the surface of the Earth and celestial bodies with different gravity, substrate roughness and atmospheric conditions, the latter including the ambient atmospheric pressure, density and viscosity Legros (2002); Lajeunesse et al. (2006); Lucas and Mangeney (2007); Singer et al. (2012); Lucas et al. (2014). However, based on the analysis of Martian flows deposits, Lucas et al. Lucas and Mangeney (2007) show that flow run-out is independent of gravity.

It is argued that friction reduction can arise because moving grains interact with the substrate, increasing random grain-velocity fluctuations at the base of the granular flow. Thus, the bulk dense flow slides over a highly agitated and low concentrated basal layer reducing the apparent basal friction Campbell (1989); Cleary and Campbell (1993); Iverson (1997); Bartelt et al. (2006); Brodu et al. (2015). Recent numerical experiments shows that the basal agitated layer can reach a height of some particles diameters and has a volume concentration as low as 0.2 Brodu et al. (2015). However, friction reduction through this mechanism seems to occurs only for high speed flows on relatively steep substrates and bounded by lateral walls on which significant friction occurs.

Goujon et al. Goujon et al. (2003) showed experimentally that for flows of relatively large particles of size $d>150 \mu \mathrm{m}$ and propagating on an inclined rough plane, the main parameter controlling flow friction was the ratio between the size of the flowing particles $(d)$ and the size of roughness $(\delta)$. They found that flow friction was maximum at $d / \delta \sim 0.5$. They also argued that the increase in the flow run-out for $d / \delta<\sim 0.5$ was probably because the particles filled the substrate interstices, thus reducing the effective roughness. However, changes in flow run-out with $d / \delta$ was almost negligible for slope angles lower 
than $\sim 18^{\circ}$. The negligible dependence of the flow run-out with $d / \delta$ on horizontal planes was confirmed by experiments of Lube et al. Lube et al. (2004) for $d>300 \mu m$ and maximum values of $d / \delta \sim 1$.

The presence of an interstitial fluid can be a key factor for friction reduction in granular flows, especially those containing high amounts of fine particles $(\sim 100 \mu \mathrm{m})$ that confer low hydraulic permeabilities Iverson (1997); Iverson and Denlinger (2001); Roche et al. (2010); Montserrat et al. (2012, 2016); Chédeville and Roche (2018); Breard et al. (2018). Excess pore fluid pressure, naturally arising from upwards fluid fluxes and/or particle settling, reduces interparticle friction by locally decreasing contact forces Iverson (1997); Iverson and Denlinger (2001); McArdell et al. (2007); Montserrat et al. (2012). Excess pore fluid pressure, high above hydrostatic levels, was measured both in laboratory experiments and in natural flows in the field Iverson (1997); Iverson et al. (2010); Roche et al. (2010); McArdell et al. (2007). Chédeville and Roche Chedeville and Roche (2014); Chédeville and Roche (2015) found that flows of fine particles on a rough substrate experienced autofluidization. This occurred as the flow particles settled into the interstices of the substrate and forced the air to escape upwards and to percolate through the flow. Autofluidization thus increased the flow run-out compared to a smooth substrate, and this effect was enhanced as the substrate roughness increased because more air was available for autofluization. On the same principle, autofluidization occurs also in collapsing beds of fine particles released from some height above a solid surface, as demonstrated by numerical simulations Breard et al. (2018) and laboratory experiments Chédeville and Roche (2018). Fine-grained mixtures can also be fluidized through mechanical vibrations that cause fluid-particle relative oscillations and related high pore fluid pressure, a phenomenon called acoustic streaming Valverde and Soria-Hoyo (2015); Soria-Hoyo et al. (2019).

Fluidization of granular flows rich in fine particles, however, is uncertain in case the atmospheric pressure is significantly lower than on Earth, as it is the case on Mars for instance $\left(4 \times 10^{-3}\right.$ to $9 \times 10^{-3}$ bar $)$. Therefore, we experimentally explore the effect of the ambient air pressure and substrate roughness on the run-out of granular flows. We perform dam-break type experiments involving different particle sizes, substrate roughness, and degrees of vacuum. To this end, we constructed a sealed channel that allowed us to make experiments up to $\sim 99 \%$ of vacuum relative to the ambient atmosphere. To our knowledge, this is the first investigation conducted under vacuum conditions and using fine particles. Previous granular flow experiments under high vacuum conditions were performed with coarser particles and showed no significant effects of the vacuum degree on flow emplacement Börzsönyi and Ecke (2006). Our results highlight the importance of the ambient fluid and bottom roughness in increasing flow-run out of fine particles $(d \sim 75 \mu \mathrm{m})$ even at low vacuum degrees, while for coarser particles $(d \geq 150 \mu m)$ both effects are negligible. 


\section{Materials and Methods}

We conducted dam-break experiments in a sealed lock-exchange channel 180 cm-long, $19.3 \mathrm{~cm}$-wide and $50 \mathrm{~cm}$-high (Figure 1). A sluice gate separates the channel from the reservoir at the upper end, where the particles are retained. This section is $100 \mathrm{~cm}$ high, so that the gate can be opened inside the device. The reservoir has a length $x_{o}=20 \mathrm{~cm}$. We generate granular flows by a rapid vertical release of the sluice gate $(<0.1 s)$. The experimental device is made of a $30 \mathrm{~mm}$-thick transparent plexiglass to permit flow visualization and to resist high degrees of vacuum. It is also equipped with a vacuum pump to reduce ambient air pressure, and the degree of vacuum is measured using a EdwardsAPG100 - XM vacuometer. The maximum degree of vacuum that can be reached in the channel system is of the order of $\sim \% 1$ of the atmospheric pressure. For the range of ambient pressures we use (1\% to $100 \%$ of the atmospheric pressure), air viscosity remains constant Börzsönyi and Ecke (2006); Bello (2017).

The bottom of the channel is covered by a $10 \mathrm{~mm}$-thick aluminum sheet over which the granular flow propagates. Different roughnesses where obtained by gluing a single layer of particles of diameter $\delta$ to the aluminum base. We tested three different bottom roughness conditions: i) aluminum roughness, ii) $\delta=1 \mathrm{~mm}$ roughness and iii) $\delta=3 \mathrm{~mm}$ roughness. Onward, the smooth aluminum roughness condition will be denoted as $\delta=0$.

We used two different types of near spherical glass beads (Ballotini, Potters Industries) with characteristics diameters $d_{1} \sim 75 \mu \mathrm{m}(\sim 40 \mu \mathrm{m}$ to $\sim 140 \mu \mathrm{m})$ and $d_{2} \sim 150 \mu \mathrm{m}(\sim 70 \mu \mathrm{m}$ to $\sim 300 \mu \mathrm{m})$, repose angles $\theta_{1}=27.1^{\circ} \pm 0.4^{\circ}$ and $\theta_{2}=27.7^{\circ} \pm 0.3^{\circ}$, and both with a particle density of $\rho_{p}=2500 \mathrm{~kg} / \mathrm{m}^{3}$. Particles where carefully poured inside the reservoir in order to achieve near constant mixture densities, $\rho_{1}=1360 \pm 15 \mathrm{~kg} / \mathrm{m}^{3}$ for $d \sim 75 \mu \mathrm{m}$-particles and $\rho_{2}=1412 \pm 6 \mathrm{~kg} / \mathrm{m}^{3}$ for $d \sim 150 \mu \mathrm{m}$-particles, resulting in initial particle

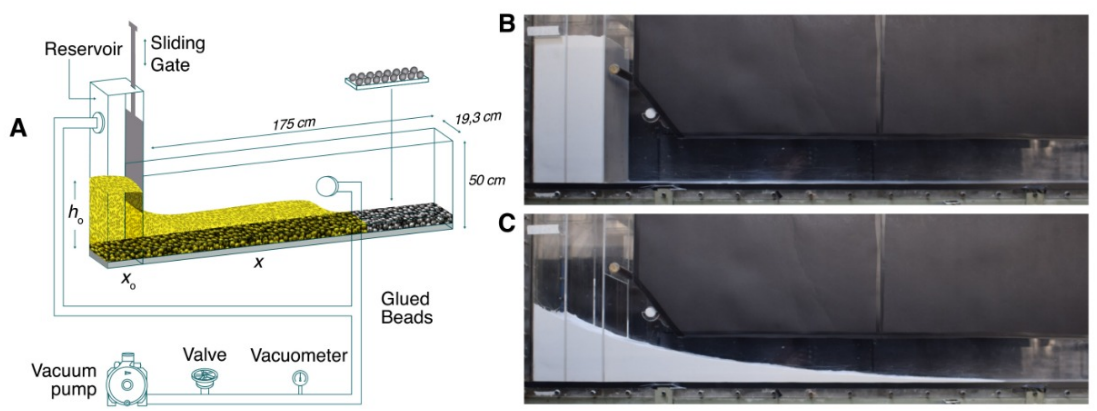

Fig. 1 A) Sketch of the experimental device. $h_{o}$ and $x_{o}$ denotes the initial height and length of the column of particles inside the reservoir, respectively, while $x$ is the flow-front position measured from the gate, B) Side view of the experimental channel before removing the gate. Particles (in white) are in the reservoir. C) Side view of the final deposit 
volume concentrations $c_{v 1}=0.54 \pm 0.01$ and $c_{v 2}=0.56 \pm 0.01$ (i.e. particlemixture porosity $\phi_{1}=0.46 \pm 0.01$ and $\phi_{2}=0.44 \pm 0.01$ ). Particles bed heights in the reservoir where varied from $h o \sim 20 \mathrm{~cm}$ to $h o \sim 40 \mathrm{~cm}$ (in terms of mass, from $\sim 10.5 \mathrm{~kg}$ to $\sim 22.5 \mathrm{~kg}$ ).

In our experiments, and due to the relatively narrow grain size range of the materials, we did not expect significant particle size segregation in the reservoir, flow or deposit. Thus, segregation was neglected in our analysis. In addition, the channel width to particle size ratio was of the order of $\sim 2550$ and $\sim 1280$ for fine and coarse particles respectively, so that negligible sidewall effects were expected. However, side wall effects seem to be responsible in reducing flow run out in case of initial high column aspect ratios $(h o / x o>1.5)$ respect to low column aspect ratios Roche et al. (2011); Montserrat et al. (2016). Nevertheless, these differences are less than the observed experimental variability and we assumed that sidewall effects had a negligible influence on our flows.

\section{Results}

\subsection{Flow run-out distance}

The run-out distance of flows of particles of size $d=75 \mu \mathrm{m}$ shows an important increase with both ambient pressure and substrate roughness. Figure 2 shows that, for these particles, the dimensionless flow run-out $\left(x_{f}^{*}=x_{f} / h_{0}\right)$ increases fairly linearly with the dimensionless ambient pressure $P *=P_{o} / P_{a t m}$ (where $P_{o}$ denotes for the ambient pressure inside the channel and $P_{a t m}$ is the atmospheric pressure in the laboratory). The dimensionless flow run-out under vacuum conditions (i.e. $P^{*}=0$ ), inferred from the best linear fits shown in Figure 2, increases from $x_{f}^{*}=2.3$ to $x_{f}^{*}=3.5$, and $x_{f}^{*}=3.8$ for smooth, $1 \mathrm{~mm}$ and $3 \mathrm{~mm}$-substrate roughnesses, respectively. This corresponds to a flow runout increase of $52 \%$ and $65 \%$, for $1 \mathrm{~mm}$ and $3 \mathrm{~mm}$ roughnesses, respectively, compared to the smooth case in the absence of an interstitial fluid. In addition, the substrate roughness increases the growth rate of the dimensionless flow run-out with the ambient pressure. While the slope of the fitted straight lines for the case of the smooth surface is 0.79 , it increases to 1.75 and 2.29 for $1 \mathrm{~mm}$ and $3 \mathrm{~mm}$-substrate roughnesses, respectively. This results in values of $x_{f}^{*}=3.1, x_{f}^{*}=5.2$ and $x_{f}^{*}=6.1$ for smooth, $1 \mathrm{~mm}$ and $3 \mathrm{~mm}$-substrate roughnesses, respectively, at laboratory ambient conditions $(P *=1)$. This corresponds to an increase of the flow run-out of $68 \%$ and $97 \%$ for $1 \mathrm{~mm}$ and $3 \mathrm{~mm}$-roughnesses, respectively, compared to the smooth case.

The flow run-out distance for particles of size $d=150 \mu \mathrm{m}$ shows to be independent of both the ambient pressure and surface roughness (Figure 2), except for the case of $\delta=3 \mathrm{~mm}$, where a slight increasing tendency of the flow run-out is observed with $P^{*}$. The dimensionless run-out for $d=150 \mu \mathrm{m}$ particles is always significantly lower than that of flows of $d=75 \mu \mathrm{m}$ particles for the same range of ambient pressure and channel roughness. Note that at 


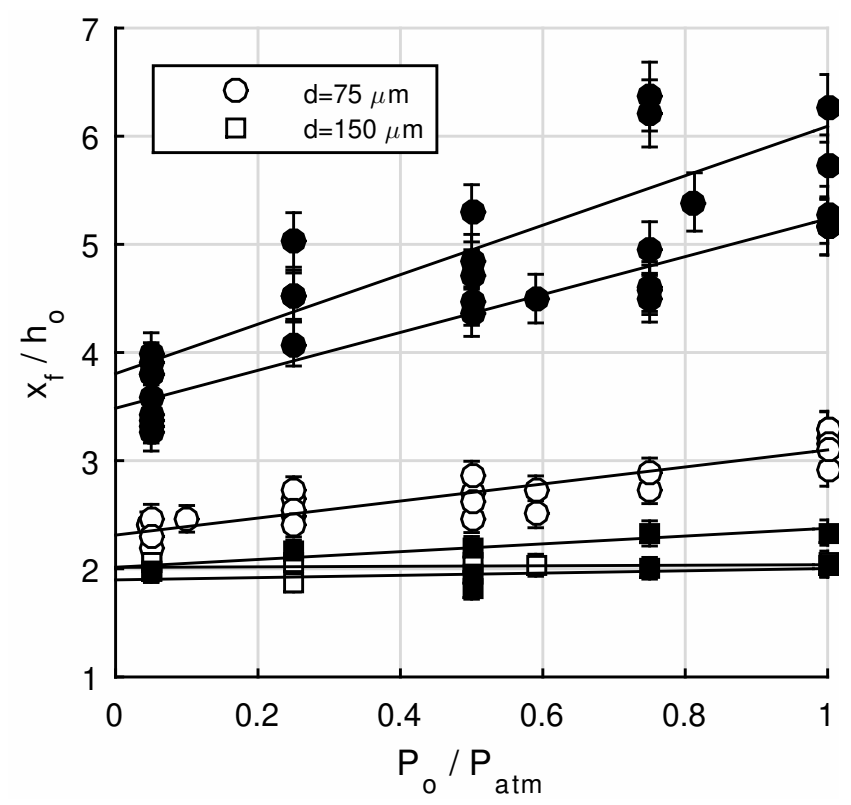

Fig. 2 Dimensionless flow run-out, $x_{f} / h_{o}$, as a function of the dimensionless ambient pressure $P_{o} / P_{a t m}$ (with $P_{o}$ the ambient pressure inside the channel and $P_{a t m}$ the atmospheric pressure in the laboratory). White, gray and dark symbols represent smooth, $1 \mathrm{~mm}$ and 3 $\mathrm{mm}$ bottom roughness respectively. Note that symbols may be larger than error bars.

vacuum conditions, the dimensionless flow run-out for $d=75 \mu \mathrm{m}\left(x_{f}^{*}=2.3\right)$ on a smooth substrate is slightly higher $(\sim 15 \%)$ than that for $d=150 \mu m$ $\left(x_{f}^{*}=2\right)$.

\subsection{Flow-front dynamics and flow morphology of fine particle mixtures}

In this section, we examine fine particles mixtures as no significant changes in the flow front dynamics and flow morphology are observed for coarser particles $(d \sim 150 \mu m)$, neither with $P^{*}$ nor $\delta$. In addition, and to simplify the analysis, we only compare the obtained results between the two roughness extremes used in the experiments (i.e. $\delta=0$ and $\delta=3 \mathrm{~mm}$ ).

Figure 3 shows the dimensionless flow front position, $x^{*}=x / h_{o}$, for $d=75 \mu m$-particles, as a function of the dimensionless time, $t^{*}=t /\left(h_{o} / g\right)^{1 / 2}$ Roche et al. (2008), where $x$ denotes the horizontal flow front position measured from the gate, $t$ is time, and $g$ is the gravitational acceleration, for different vacuum conditions and for a smooth substrate $(\delta=0)$. The flow front propagates in three different phases, as known for flows under atmospheric pressure conditions Lajeunesse et al. (2005); Roche et al. (2008); Xu et al. (2016); Lube et al. (2005). Under atmospheric conditions $\left(P^{*}=1\right)$, Figure 3 shows a first phase for which the flow front accelerates (first phase) until it reaches a constant front velocity $U$ equal to $\alpha\left(g h_{o}\right)^{1 / 2}$, where $\alpha$ is a pro- 
portionality constant close to $\sim 1$ Roche et al. (2008). The constant velocity phase occurs for $\sim 1.5<t^{*}<\sim 3.0$. A second transition occurs at $t^{*} \sim 3.0$, where the flow starts decelerating until it comes to halt at $t^{*} \sim 5-5.5$.

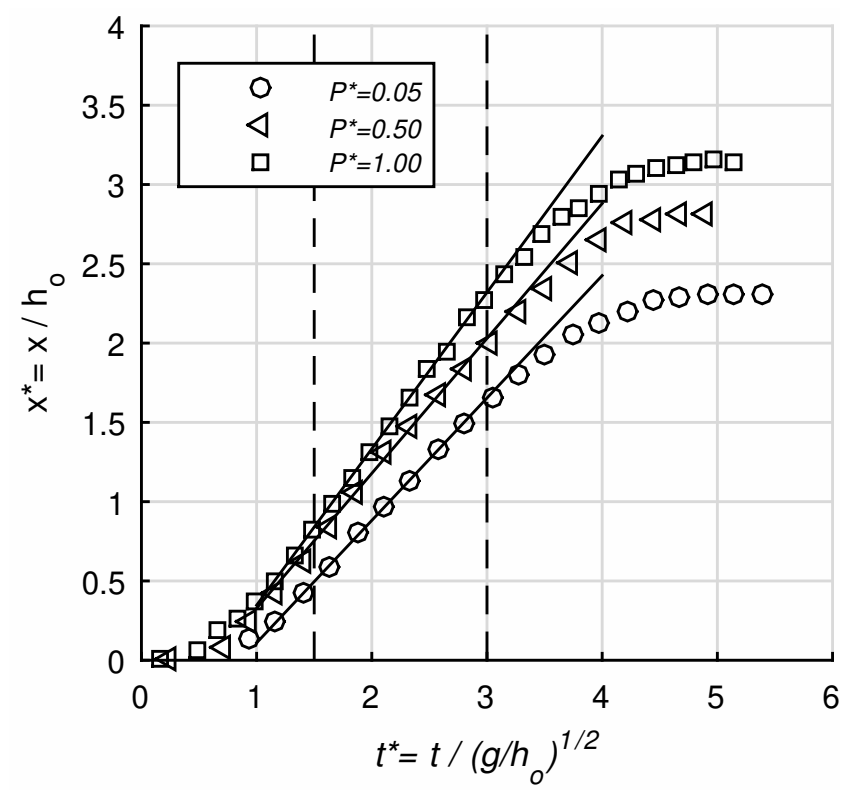

Fig. 3 Dimensionless flow front position $x^{*}$ for different values of $P^{*}$ and $\delta=0$

The same trend is observed at reduced atmospheric conditions (Figure 3), with the transitions between phases occurring at the same values of $t^{*}$ than for laboratory ambient pressure (i.e. $P^{*}=1$ ). The main effect of the ambient pressure is a velocity decrease in the constant-velocity phase, with $\alpha$ decreasing from $\alpha=0.99$ at laboratory atmospheric conditions to $\alpha=0.85$ and $\alpha=0.77$ at $P^{*}=0.50$ and $P^{*}=0.05$, respectively.

Figure 4 shows that the front position for fine particles flows $(d=75 \mu \mathrm{m})$ at $\delta=0$ and $\delta=3 \mathrm{~mm}$ and different vacuum degrees are almost identical until $t^{*} \sim 3.0$. However, for rough substrates $(\delta=3 \mathrm{~mm})$, the constant velocity phase lasts longer. For example, for $\delta=3 \mathrm{~mm}$, the transition between the second and third phase occurs at $t^{*} \sim 5$. In addition, increasing roughness significantly reduces the front deceleration, thus increasing the flow run-out and duration Chedeville and Roche (2014); Chédeville and Roche (2015). While flows on a smooth substrate stop at $t^{*} \sim 5-5.5$, almost independently of $P^{*}$, at $\delta=3 \mathrm{~mm}$ flow duration last up to $t^{*} \sim 7, t^{*} \sim 8$ and $t^{*} \sim 9$ for $P^{*}=0.05$, $P^{*}=0.50$ and $P^{*}=1.00$, respectively.

These kinematics can be complemented considering the flow morphology, which varies very little with the channel roughness until the end of the constant velocity phase for smooth surfaces $\left(t^{*} \sim 3\right)$, regardless of $P *$ (Figure 5). For $t^{*}>3$, the flow length increases with the substrate roughness and this is 

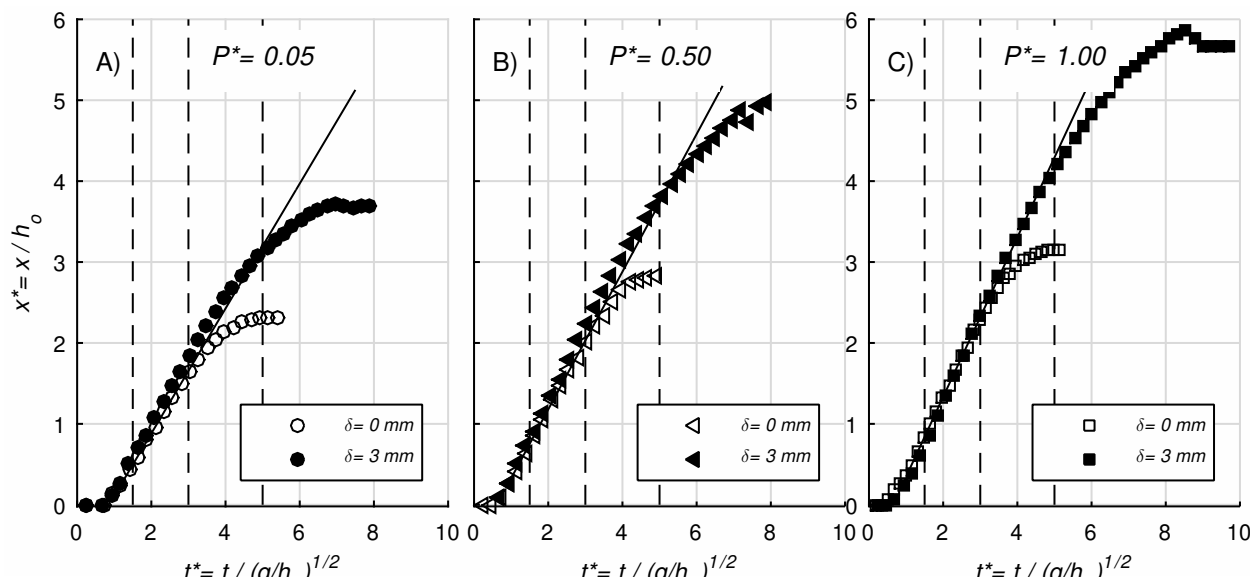

Fig. 4 Dimensionless flow front position, $x^{*}$, for different values of $P^{*}$ and $\delta$, for fine $75 \mu m$ particles

mainly because a thin flow head arises from the flow body, even after the latter has stopped Chedeville and Roche (2014). Slight differences in the position of the center of area (equivalent to the center of mass in 3D) of the flow for smooth and $3 \mathrm{~mm}$ rough surfaces confirm that the increasing flow length with roughness is due to the very thin frontal part of the flow that propagates downstream and causes long run-out.

\section{Discussion}

Sustained high pore fluid pressure has been pointed out as one of the primary friction reduction mechanisms in experimental flows of initially fluidized fine $(<\sim 100 \mu \mathrm{m})$ granular materials propagating on smooth or rough surfaces at earth atmospheric conditions Roche et al. (2008, 2010); Montserrat et al. (2012, 2016); Chedeville and Roche (2014); Chédeville and Roche (2015); Breard et al. (2018); Chédeville and Roche (2018). Notice that initially non-fluidized flows with shorter run-out distances have the ability to self-generate excess pore fluid pressure to near $\sim 15 \%$ of the weight of the particle, possibly because of granular mixture compaction Roche et al. (2010) or by air incorporation at the flow front Bareschino et al. (2008). However, this last mechanism has shown to be negligible in experimental flows Chédeville and Roche (2015). Recent dam-break experiments show that the mixture porosity is correlated with flow velocity as it decreases during flow acceleration (i.e. mixture dilation) and increases during flow deceleration (i.e. mixture compaction) Xu et al. (2016). In case of granular compaction, pore pressure rises by the compression of air trapped in the interstices if the time scale for particles rearrangement $\left(T_{R}\right)$ is small compared with the time scale for vertical pore pressure diffusion $\left(T_{D}\right)$ Homan et al. (2014). The opposite occurred in case of mixture dilation (i.e. pore pressure drops when the mixture and pores dilate). For a given change in 

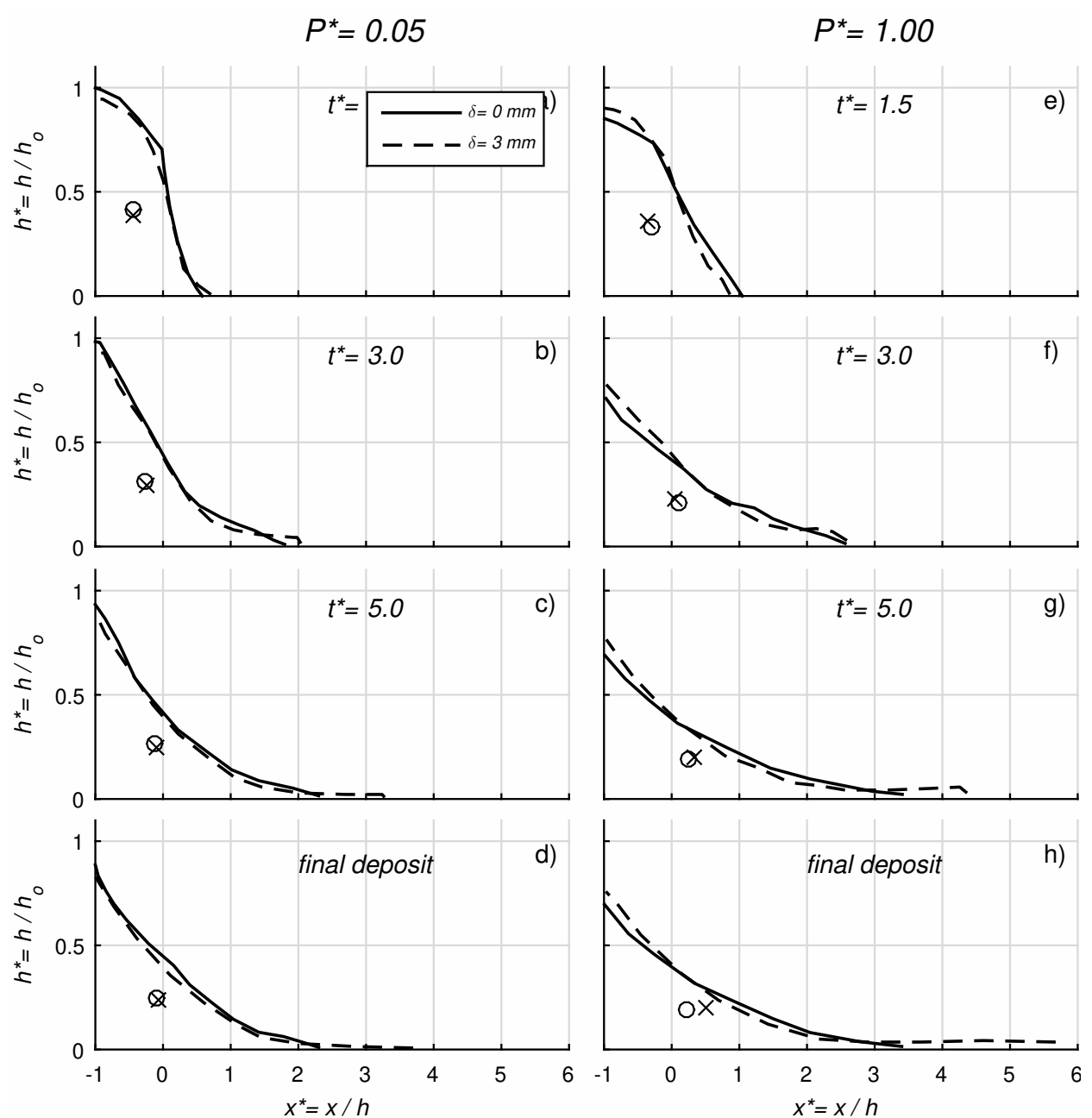

Fig. 5 Flow morphology for different $\delta$ and $P^{*}$. $\circ$ and $\times$ denotes for the center of area of the flowing mixture for $\delta=0$ and $\delta=3 \mathrm{~mm}$, respectively.

air volume $\left(\Delta V_{a}\right)$, and assuming isothermal air compression, the upper limit for pore pressure variations $(\Delta P)$ respect to the ambient pressure $\left(P_{o}\right)$ can be approximated as Homan et al. (2014):

$$
\Delta P=-P_{o} \frac{\Delta V_{a}}{V_{a}}
$$

where $V_{a}$ is the volume of air in the interstices and $\Delta V_{a}$ is defined positive for air dilation and negative for air compression. In equation (1), non linear terms have been neglected Homan et al. (2014).

As $P_{o}=P^{*} P_{a t m}$, equation (1) shows that for similar changes in the air volume between grains, $|\Delta P|$ linearly decreases with the degree of vacuum 
$\left(\Delta P \sim P^{*}\right)$. Thus, autofluidization is possible even under reduced atmospheric conditions, and decreasing the ambient pressure will linearly decrease the amount of pore pressure changes. This can explain the observed linear trends between the flow run-out and the degree of vacuum $\left(x_{f} / h_{o} \sim P^{*}\right.$, see Figure 2 ), at least for the case $\delta=0$ and $d=75 \mu m$-particles. In this sense, reducing $P_{o}$ increases the effective flow friction, which also agrees with the observed reductions in flow duration and flow-front velocities during the constant velocity phase.

For flows over rough substrates $(\delta=1 \mathrm{~mm}$ and $\delta=3 \mathrm{~mm})$, fluidization can arise because of particles falling into the substrate interstices and forcing the air to percolate upwards through the granular flow Chedeville and Roche (2014); Chédeville and Roche (2015). The amount of pore fluid pressure due to drag interactions $(\Delta p)$ increases with air velocity and can be accounted in packed beds by the semi-empirical Ergun equation Gibilaro (2001), here expressed in terms of the degree of fluidization $\left(\Delta p^{*}=\Delta p / P_{L}\right)$ of a granular column of height $h$ and bulk density $\rho$ :

$$
\Delta p^{*}=\frac{\Delta p}{P_{L}}=150 \frac{\mu_{g} U_{g}}{\rho g d^{2}} \frac{(1-\phi)^{2}}{\phi^{3}}+1.75 \frac{\rho_{g} U_{g}^{2}}{\rho g d} \frac{1-\phi}{\phi^{3}}
$$

where $\mu_{g}$ is the gas dynamic viscosity, $U_{g}$ is the superficial gas velocity (defined as the flow rate per unit cross sectional area), $\rho_{g}$ is the gas density and $\phi$ is the particle-mixture porosity (defined previously). We assumed that changes of porosity was negligible during flow emplacement, making the Ergun equation relevant for describing fluidization. The first and second terms at the righthand of equation 2 accounts for viscous and inertial fluidization, respectively.

$\Delta p^{*}=1$ means that the entire weight of the particle bed is supported by air drag, which occurs at a minimum value of $U_{g}$ called the minimum fluidization velocity, $U_{m f}$. Solving equation 2 for $\Delta p^{*}=1$ results in $U_{m f}=11 \mathrm{~mm} / \mathrm{s}$ and $U_{m f}=32 \mathrm{~mm} / \mathrm{s}$ for $d=75 \mu \mathrm{m}$ and $d=150 \mu \mathrm{m}$-particles, respectively. These values scale with previous experimental measurements done on similar materials Roche et al. (2004). Chédeville and Roche Chedeville and Roche (2014) estimate that particles falling into the interstices generate upward air fluxes above $U_{m f}$-values due to the high settling velocities of the particles. For the estimated values of $U_{m f}$, the first term on the right hand side of equation 2 is $\sim 1$, while the second term is $\sim 10^{-3}$, meaning that fluidization is mainly due to viscous drag. Thus, for the range of $P$-values used for this experiments, for which $\mu$ is constant, autofluidization related to a rough substrate is always possible, even at high vacuum conditions. This explains the increasing runout of $d=75 \mu \mathrm{m}$-particles mixtures compared to a smooth substrate even at very low ambient pressure conditions $\left(P^{*} \sim 0.05\right)$. Umf for $d=150 \mu m$ particles is larger than for $d=75 \mu \mathrm{m}$-particles. As both types of particles fall into the interstices as about the same velocity, then the interstitial air velocity should be in the same order in both cases. However,this result in smaller $\Delta p^{*}$ for $d=150 \mu m$-particle mixtures, explaining the almost null effect of $P^{*}$ in the run-out of these flows. The slight increase of $x_{f}^{*}$ with $P^{*}$ observed for $\delta=3 \mathrm{~mm}$, suggests that higher volumes of air trapped into the interstices 
are able to sustain vertical air fluxes for longer periods, promoting a weak fluidization compared with $d=75 \mu \mathrm{m}$-particles flows.

An alternative (or complementary) friction reduction mechanism, consisting in the development of a low density layer at the flow bottom because of flow particles colliding with those of the bottom roughness, may also be considered. In this context, the flow run-out is expected to be a function of $d / \delta$ Goujon et al. (2003). In the case of a smooth surface (aluminum substrate) we assume $d / \delta=1$, as it has been observed that the flow rides over a thin layer of the same particles deposited after the passage of the flow-front Lube et al. (2004). Thus, for $d=75 \mu m$-particles $d / \delta=1-0.025$, while for $d=150 \mu \mathrm{m}$-particles $d / \delta=1-0.05$. Although $d / \delta$ varies in a similar range for both types of particles, the flow run-out with $d / \delta$ for $d=150 \mu m$-particles does not vary significantly. This suggests that viscous fluidization controls the flow mechanism of fine granular mixtures and confirms that, in the absence of autofluidization, $d / \delta$ does not control the flow run-out in horizontal channels.

\section{Conclusions}

Our results confirm that viscous air-particle interactions are an important friction reduction mechanism for fine-grained granular flows. In our experiments, the relative increase of flow run-out with the substrate roughness is reduced as the ambient pressure decreases, but such increase is still significant $(65 \%$, from $\delta=0$ to $3 \mathrm{~mm}$ ) even at $P^{*}=0.05$ (Figure 2). This suggests that the autofluidization mechanism acting in flows of fine particles on rough substrate and at atmospheric pressure Chedeville and Roche (2014); Chédeville and Roche (2015) operates as well at lower pressures. This can be explained because viscosity remains constant for the range of vacuum conditions explored in this study and because, for particles of this size range, fluidization is dominated by fluid viscosity Bello (2017); Roche et al. (2008).

The above-mentioned friction reduction mechanisms does not act for coarser particle materials $(d \sim 150 \mu m)$. This can be explained as the air initially present in the substrate interstices is expelled upwards at lower velocities compared with the minimum fluidization velocity $\left(U_{m f}\right)$ of the coarse particles (see Chédeville and Roche Chedeville and Roche (2014) for experiments at $P^{*}=1$ ) or because the amount of air trapped in the interstices is not enough to fluidize the particle mixture over a significant duration. An exception occurs for $\delta=3 \mathrm{~mm}$, where a slight influence of $P^{*}$ in the flow run-out is observed. In addition, for coarser $d \sim 150 \mu m$-particles, the increasing roughness does not have significant effects on the flow run-out, even for a similar range of $d / \delta$ compared with $d=75 \mu m$-particles flows. Thus, in the absence of fluidization capacity of the flowing mixture, increasing roughness shows not to be an important friction reduction mechanism in granular flows. However, this mechanism could become important for high-velocity flows on steep substrates Brodu et al. (2015). 
Regarding the motion of the flow front of fine-grained mixtures, decreasing the ambient pressure mainly results in a decrease in velocity and duration of the constant velocity phase. This is a consequence of the reduction of the autofluidization capacity, proportional to $|\Delta P|$, which causes increasing friction. Increasing $\delta$ increases the flow run-out by increasing the time of the constant velocity phase and the stopping phase. This is because, for larger $\delta$, the air is expelled from the substrate for longer duration as more air is trapped initially in their interstices. However, the increase in flow run-out is due to a thin flowing frontal layer that spreads from the flow body at $t^{*} \sim 3$, which represents a little amount of the total mass. Thus, the run-out of the bulk flow, represented by the run-out of the center of area of the avalanche (see Figure 5), is almost independent of $d / \delta$.

Our findings have implications for granular mass flows on extraterrestrial planets with reduced atmospheric pressure. They suggest that fluidization caused by viscous drag may occur through vertical gas fluxes within the granular flow, even at low ambient pressure. This is likely to occur when flows propagating on rough substrates contain high amounts of fine particles that settle into the substrate interstices. However, fluidization may also arise from air compression (i.e. increasing pore pressure) during fast contraction of the particle network. This second mechanism decreases when reducing the atmospheric pressure, thus increasing flow friction and reducing the flow run-out. This is likely to be important for fine particle flows, where the time for particle rearrangements is small compared with the time for pore pressure diffusion

Acknowledgements This work was supported by the Advanced Mining Technology Center (AMTC) and Departamento de Ingeniería Civil, form Universidad de Chile, the French National Research Institute for Sustainable Development (IRD, France) and the Chilean National Commission for Scientific and Technological Research, CONICYT, through Fondecyt Projects 1130910 and 11130254 and PIA Project AFB180004. We thank P. Mendoza and two anonymous reviewers for helpful comments on our work. We also thank C. González for his assistance with graphics. This is Laboratory of Excellence ClerVolc contribution No XXX.

Compliance with Ethical Standards The authors declare that they have no conflicts of interest. The study was supported by the Advanced Mining Technology Center (AMTC) from Universidad de Chile, and the Chilean National Commission for Scientific and Technological Research, CONICYT, through Fondecyt Projects 1130254.

\section{References}

Bareschino P, Lirer L, Marzocchella A, Petrosino P, Salatino P (2008) Self-fluidization of subaerial rapid granular flows. Powder Technology 182(3):323-333, DOI 10.1016/j.powtec.2007.12.010

Bartelt P, Buser O, Platzer K (2006) Fluctuation dissipation relations for granular snow avalanches. Journal of Glaciology 52(179):631-643, DOI $10.3189 / 172756506781828476$ 
Bello I (2017) Vacuum and Ultravacuum. CRC Press, DOI $10.1201 / 9781315155364$

Börzsönyi T, Ecke RE (2006) Rapid granular flows on a rough incline: Phase diagram, gas transition, and effects of air drag. Physical Review E 74(6):61,301

Breard ECP, Dufek J, Lube G (2018) Enhanced Mobility in Concentrated Pyroclastic Density Currents: An Examination of a SelfFluidization Mechanism. Geophysical Research Letters 45(2):654-664, DOI 10.1002/2017GL075759

Brodu N, Delannay R, Valance A, Richard P (2015) New patterns in high-speed granular flows. Journal of Fluid Mechanics 769:218-228, DOI $10.1017 /$ jfm.2015.109

Campbell CS (1989) Self-lubrication for long runout landslides. The Journal of Geology pp 653-665

Chedeville C, Roche O (2014) Autofluidization of pyroclastic flows propagating on rough substrates as shown by laboratory experiments. Journal of Geophysical Research: Solid Earth 119(3):1764-1776, DOI 10.1002/2013JB010554

Chédeville C, Roche O (2015) Influence of slope angle on pore pressure generation and kinematics of pyroclastic flows: insights from laboratory experiments. Bulletin of Volcanology 77(11):96, DOI 10.1007/s00445-015-0981-4

Chédeville C, Roche O (2018) Autofluidization of collapsing bed of fine particles: Implications for the emplacement of pyroclastic flows. Journal of Volcanology and Geothermal Research 368:91-99, DOI 10.1016/j.jvolgeores.2018.11.007

Cleary PW, Campbell CS (1993) Self-lubrication for Long Runout Landslides: Examination by computer simulation. Journal of Geophysical Research: Solid Earth 98(B12):21,911-21,924, DOI 10.1029/93JB02380

Delannay R, Valance A, Mangeney A, Roche O, Richard P (2017) Granular and particle-laden flows: from laboratory experiments to field observations. Journal of Physics D: Applied Physics 50(5):053,001, DOI 10.1088/1361$6463 / 50 / 5 / 053001$

Gibilaro LG (2001) Fluidization dynamics. Elsevier

Goujon C, Thomas N, Dalloz-Dubrujeaud B (2003) Monodisperse dry granular flows on inclined planes: Role of roughness. The European Physical Journal E 11(2):147-157, DOI 10.1140/epje/i2003-10012-0

Homan T, Gjaltema C, van der Meer D (2014) Collapsing granular beds: The role of interstitial air. Physical Review E 89(5):052,204, DOI 10.1103/PhysRevE.89.052204

Iverson RM (1997) The Physics of Debris. Review of Geophysics 35(97):245296, DOI 10.1029/97RG00426

Iverson RM, Denlinger RP (2001) Flow of variably fluidized granular masses across three-dimensional terrain: 1. Coulomb mixture theory. Journal of Geophysical Research: Solid Earth 106(B1):537-552, DOI 10.1029/2000JB900329

Iverson RM, Logan M, LaHusen RG, Berti M (2010) The perfect debris flow? Aggregated results from 28 large-scale experiments. Journal of Geophysical 
Research: Earth Surface 115(F3):n/a -n/a, DOI 10.1029/2009JF001514

Lajeunesse E, Monnier JB, Homsy GM (2005) Granular slumping on a horizontal surface. Physics of fluids 17:103,302, DOI doi.org/10.1063/1.2087687

Lajeunesse E, Quantin C, Allemand P, Delacourt C (2006) New insights on the runout of large landslides in the Valles-Marineris canyons, Mars. Geophysical Research Letters 33(4), DOI 10.1029/2005GL025168

Legros F (2002) The mobility of long-runout landslides. Engineering Geology 63(3):301-331, DOI 10.1016/S0013-7952(01)00090-4

Lube G, Huppert HE, Sparks RSJ, Hallworth MA (2004) Axisymmetric collapses of granular columns. Journal of Fluid Mechanics 508(1):175-199, DOI $10.1017 /$ S0022112004009036

Lube G, Huppert HE, Sparks RSJ, Freundt A (2005) Collapses of twodimensional granular columns. Physical Review E 72(4):041,301, DOI 10.1103/PhysRevE.72.041301

Lucas A, Mangeney A (2007) Mobility and topographic effects for large Valles Marineris landslides on Mars. Geophysical research letters 34(10):L10,201, DOI 10.1029/2007GL029835

Lucas A, Mangeney A, Ampuero JP (2014) Frictional velocity-weakening in landslides on Earth and on other planetary bodies. Nature communications 5, DOI 10.1038/ncomms4417

McArdell BW, Bartelt P, Kowalski J (2007) Field observations of basal forces and fluid pore pressure in a debris flow. Geophysical Research Letters 34(7), DOI 10.1029/2006GL029183

Montserrat S, Tamburrino A, Roche O, Niño Y (2012) Pore fluid pressure diffusion in defluidizing granular columns. Journal of Geophysical Research 117(F2):F02,034, DOI 10.1029/2009JB007133

Montserrat S, Tamburrino A, Roche O, Niño Y, Ihle CF (2016) Enhanced runout of dam-break granular flows caused by initial fluidization and initial material expansion. Granular Matter 18(1):1-9, DOI 10.1007/s10035-0160604-6

Roche O, Gilbertson MA, Phillips JC, Sparks RSJ (2004) Experimental study of gas-fluidized granular flows with implications for pyroclastic flow emplacement. Journal of Geophysical Research: Solid Earth 109(B10), DOI 10.1029/2003JB002916

Roche O, Montserrat S, Niño Y, Tamburrino A (2008) Experimental observations of water-like behavior of initially fluidized, dam break granular flows and their relevance for the propagation of ash-rich pyroclastic flows. Journal of Geophysical Research 113(B12):B12,203, DOI 10.1029/2008JB005664

Roche O, Montserrat S, Niño Y, Tamburrino A (2010) Pore fluid pressure and internal kinematics of gravitational laboratory air-particle flows: insights into the emplacement dynamics of pyroclastic flows. Journal of Geophysical Research 115:B09,206, DOI 10.1029/2009JB007133

Roche O, Attali M, Mangeney A, Lucas A (2011) On the run-out distance of geophysical gravitational flows: Insight from fluidized granular collapse experiments. Earth and Planetary Science Letters 311(3):375-385, DOI 10.1016/j.epsl.2011.09.023 
Singer KN, McKinnon WB, Schenk PM, Moore JM (2012) Massive ice avalanches on Iapetus mobilized by friction reduction during flash heating. Nature Geoscience 5(8):574-578, DOI doi.org/10.1038/ngeo1526

Soria-Hoyo C, Valverde JM, Roche O (2019) A laboratory-scale study on the role of mechanical vibrations in pore pressure generation in pyroclastic materials: implications for pyroclastic flows. Bulletin of Volcanology 81(2):12, DOI 10.1007/s00445-019-1271-3

Valverde JM, Soria-Hoyo C (2015) Vibration-induced dynamical weakening of pyroclastic flows: Insights from rotating drum experiments. Journal of Geophysical Research: Solid Earth 120(9):6182-6190, DOI 10.1002/2015JB012317

Xu X, Sun Q, Jin F, Chen Y (2016) Measurements of velocity and pressure of a collapsing granular pile. Powder Technology 303:147-155, DOI $10.1016 /$ j.powtec.2016.09.036 